\title{
Tumor Invasion of the Prostatic Ducts and Acini
}

National Cancer Institute

\section{Source}

National Cancer Institute. Tumor Invasion of the Prostatic Ducts and Acini. NCI

Thesaurus. Code C160692.

A morphologic finding indicating the presence of a malignant cellular infiltrate invading the ductal and acinar structures of the prostate gland. 